\title{
Doping and electrical properties of amorphous silicon carbon nitride films
}

\author{
Y.C. Chou ${ }^{\mathrm{a}}$, S. Chattopadhyay ${ }^{\mathrm{a}}$, L.C. Chen ${ }^{\mathrm{a}, *}$, Y.F. Chen ${ }^{\mathrm{b}}$, K.H. Chen ${ }^{\mathrm{c}}$ \\ ${ }^{a}$ Centre for Condensed Matter Sciences, National Taiwan University, Taipei 106, Taiwan, ROC \\ ${ }^{\mathrm{b}}$ Department of Physics, National Taiwan University, Taipei 106, Taiwan, ROC \\ ${ }^{\mathrm{c}}$ Institute of Atomic and Molecular Sciences, Academia Sinica, Taipei 106, Taiwan, ROC
}

\begin{abstract}
Electrical properties and annealing behaviour of undoped and doped amorphous silicon carbon nitride $\left(\mathrm{a}-\mathrm{SiC} \mathrm{N}_{y}\right)$ thin films, deposited by ion beam sputtering techniques, have been studied. Doping of the a-SiC $\mathrm{N}_{y}$ thin films with magnesium (Mg), and phosphorous (P) was carried out by ion implantation techniques, and subsequent annealing effect on the electrical conductivity $(\sigma)$ and activation energies for electrical conduction have been reported. It was found that the undoped films were insulating with electrical conductivities in the range of $10^{-6}-10^{-8} \mathrm{~S} / \mathrm{cm}$. Annealing of these films at high temperatures aided in some structural relaxation and hence an increase in $\sigma$ by several orders of magnitude without showing any indications for crystallization. Suitable doping $(\mathrm{Mg})$ of the films resulted in increased $\sigma$, and in some cases of low phosphorous doping a decrease in $\sigma$ was also found which indicated that the films may be intrinsically p-type.
\end{abstract}

(C) 2003 Elsevier Science B.V. All rights reserved.

Keywords: Physical vapour deposition; Ion implantation; Electrical conductivity; Photoelectron spectroscopy

\section{Introduction}

The family of carbon based covalent materials continues to provide newer directions to material science research. Diamond and silicon carbide group of materials for example, along with the crystalline carbon nitrides, have created avenues for both experimental and theoretical studies. With the advent of nanoscale science they still remain a formidable family that promises to deliver in several fronts of material science. The reports of nanotubes, nanorods and nanotips of carbon or silicon carbide or silicon carbon nitride $\left(\mathrm{SiC}_{x} \mathrm{~N}_{y}\right)$ support such claims. $\mathrm{SiC}_{x} \mathrm{~N}_{y}$ material, although relatively new to this family, have shown interesting optical [1], mechanical [2] and thermal [3] properties, owing to the small size and covalent nature of their constituent atoms. Crystalline $\mathrm{SiC}_{x} \mathrm{~N}_{y}\left(\mathrm{c}-\mathrm{SiC}_{x} \mathrm{~N}_{y}\right)$ films exhibited a direct and wide band gap of $3.8 \mathrm{eV}$ and an optical emission approximately $2.8 \mathrm{eV}[1,4]$. Nanoindentation measurements on the crystalline $\mathrm{SiC}_{x} \mathrm{~N}_{y}$ suggested its hardness and bulk modulus to be in the vicinity of 30 and $322 \mathrm{GPa}$, respectively [2], whereas for amorphous $\operatorname{SiC}_{x} \mathrm{~N}_{y}$ (a$\mathrm{SiC}_{x} \mathrm{~N}_{y}$ ) films, the hardness value was approximately 22

\footnotetext{
*Corresponding author. Tel.: +886-2-2366-8228; fax: +886-22362-0200.

E-mail address: chenlc@ccms.ntu.edu.tw (L.C. Chen).
}

GPa [2] and a Young's modulus of approximately 245 $\mathrm{GPa}[5]$.

Although optoelectronic, mechanical and thermal properties of a- $\mathrm{SiC}_{x} \mathrm{~N}_{y}$ have been reported, information on their electrical properties and doping efficiencies has been rather limited. Organosilicon polymer derived nonstoichiometric $\mathrm{SiC}_{x} \mathrm{~N}_{y}$ has been reported to have high electrical conductivity [6] where nitrogen was believed to be a dopant in the ceramic matrix. Electrical properties of crystalline compacts derived out of hot-pressed $\mathrm{Si}-\mathrm{C}-\mathrm{N}$ powders were also reported [7]. Haluschka et al. [8] demonstrated the effects of chemical composition, solid state structure and microstructure of the polysilazane derived silicon carbonitride ceramics on their electrical properties. The amorphous phase we are investigating is derived from a physical vapour deposition of the constituent $\mathrm{Si}, \mathrm{C}$ and $\mathrm{N}$ atoms in a thin film form. This paper presents a systematic study on the electrical conductivity in $\mathrm{a}-\mathrm{SiC}_{x} \mathrm{~N}_{y}$, with specific treatments such as annealing and doping through ion implantation.

\section{Experimental}

The a-SiC $\mathrm{N}_{y}$ samples were deposited via ion beam sputtering (IBS) technique. A 3-cm Kaufmann type ion 
source was used for sputtering targets of laminated silicon carbide or silicon and graphite in nitrogen ambient. A detail of the IBS reactor is given elsewhere [9]. The films were grown on quartz substrates for the electrical conductivity measurements and on silicon for other characterisations. Ion implantation technique was adopted for doping the films. An ULVAC IMX-3500 ion implanter was used at $75 \mathrm{KeV}$ to dope the samples with zinc $(\mathrm{Zn})$, magnesium $(\mathrm{Mg})$ and phosphorus $(\mathrm{P})$ at different incident ion fluxes varying from $10^{12}$ to $10^{16}$ ions $/ \mathrm{cm}^{2}$. The annealing of the films were carried out by rapid thermal processing (RTP) in controlled atmosphere. RTP uses rapid heating of the samples to the desired temperature and a shorter hold time (2-10 min) unlike other conventional annealing techniques. The a-SiC $\mathrm{N}_{y}$ films on quartz were systematically studied for the electrical conductivity $(\sigma)$ by the common two-probe technique. Gold electrodes were evaporated on to the samples for proper contact whose ohmic characteristics were then verified by the linear currentvoltage $(I-V)$ characteristics. The chemical composition and bondings in the films were determined by Auger (AES) depth profile and high resolution scans of $\mathrm{Si}(2 \mathrm{p})$, $\mathrm{B}(1 \mathrm{~s}), \mathrm{C}(1 \mathrm{~s})$ and $\mathrm{N}(1 \mathrm{~s})$ peaks by X-ray photoelectron spectroscopy (XPS). A PHI 1600 system was used for the XPS measurements. A Perkin-Elmer scanning Auger nanoprobe system (SAN 760) was used for Auger electron spectroscopy (AES). Depth profiling of the doped samples were also done using secondary ion mass spectroscopy (SIMS) after implantation.

\section{Results}

The $\mathrm{a}-\mathrm{SiC}_{x} \mathrm{~N}_{y}$ samples were first studied for their composition and depth profiles using AES. A representative composition depth profile is shown in Fig. 1,
Table 1

Composition and electrical conductivity of a- $\mathrm{SiC}_{x} \mathrm{~N}_{y}$ films having different carbon content

\begin{tabular}{llll}
\hline $\begin{array}{l}\text { Silicon } \\
\text { content } \\
\text { (at.\%) }\end{array}$ & $\begin{array}{l}\text { Carbon } \\
\text { content } \\
\text { (at.\%) }\end{array}$ & $\begin{array}{l}\text { Nitrogen } \\
\text { content } \\
\text { (at.\%) }\end{array}$ & $\begin{array}{l}\text { Electrical } \\
\text { conductivity } \\
(\mathrm{S} / \mathrm{cm})\end{array}$ \\
\hline 21 & 47 & 32 & $2.33 \times 10^{-8}$ \\
20 & 50 & 30 & $6.3 \times 10^{-7}$ \\
20 & 55 & 25 & $5.6 \times 10^{-6}$ \\
\hline
\end{tabular}

which reveals the homogeneity of composition along different depth of the sample. The sample studied had 50 at.\% carbon (C), 25 at.\% nitrogen $(\mathrm{N}), 20$ at.\% silicon $(\mathrm{Si})$ and less than 10 at.\% oxygen $(\mathrm{O})$ in it.

Films with different compositions and $\sigma$ are tabulated in Table 1. Films with higher carbon content was found to have a higher $\sigma$. Fig. 2 shows the deconvoluted $\mathrm{C} 1 \mathrm{~s}$ XPS spectra for the films with carbon contents of 47 and 55 at.\%, respectively. The main contribution to the peak comes from the $\mathrm{C}\left(\mathrm{sp}^{2}\right)-\mathrm{C}$ and $\mathrm{C}(\mathrm{sp})-\mathrm{N}$ with binding energies of 284.6 and $286.5 \mathrm{eV}$, respectively [3]. The film with higher carbon content had a $37 \%$ higher ratio of the $\mathrm{C}(\mathrm{sp})-\mathrm{N}$ bonds to $\mathrm{C}\left(\mathrm{sp}^{2}\right)-\mathrm{C}$ bonds relative to the lower carbon content film.

The sensitivity of $\sigma$ towards the carbon content indicated a rather strong structural dependence, and a simple way to alter the structure of a network is annealing whereby some stress in the network and some defects could be efficiently removed. All electrical measurements that will be discussed were carried out on the a- $\mathrm{SiC}_{x} \mathrm{~N}_{y}$ sample with 50 at.\% carbon, if not specifically mentioned. Fig. 3 shows the changes in $\sigma$ for an undoped a- $\mathrm{SiC}_{x} \mathrm{~N}_{y}$ sample with different annealing temperatures. The electrical conductivity increased by four orders of magnitude after annealing at temperatures

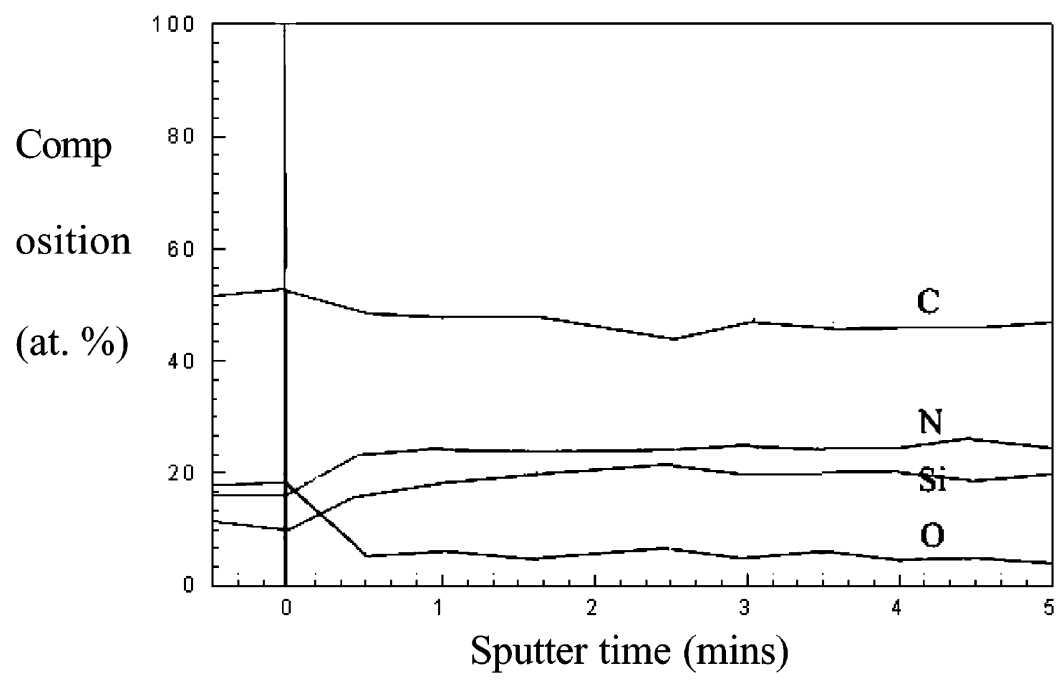

Fig. 1. Representative AES depth profile of an $a-S_{x}{ }_{x} N_{y}$ film showing the uniform composition along the thickness of the sample. 

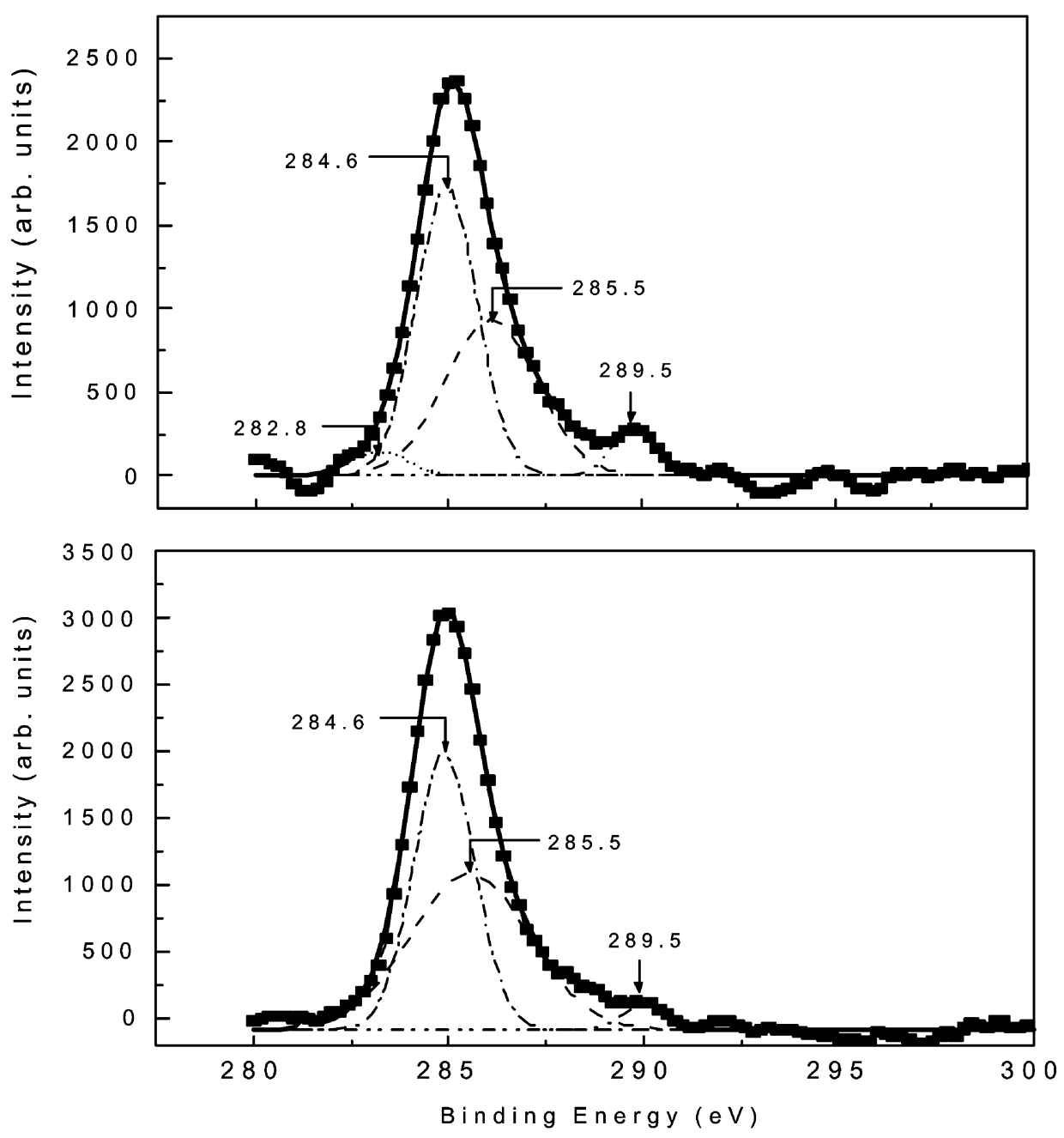

Fig. 2. Deconvoluted XPS C(1s) spectra for $a-S_{i} N_{y}$ films with (a) 47 and (b) 55 at.\% of carbon.

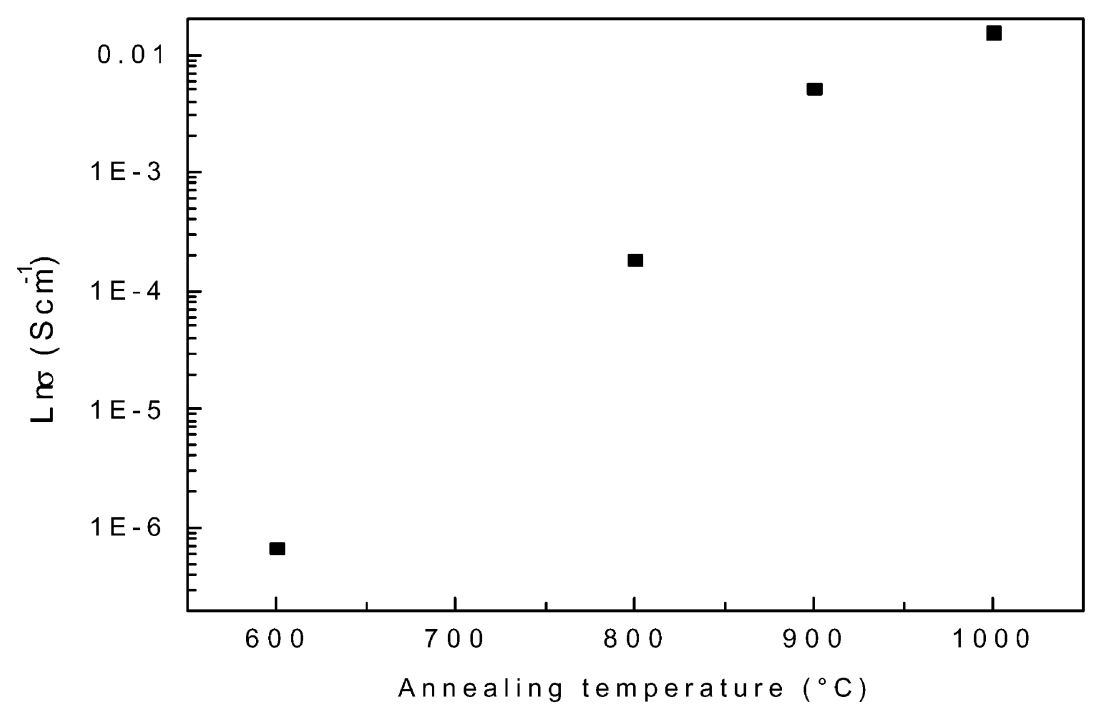

Fig. 3. Variation of the room temperature electrical conductivity $(\sigma)$ in undoped a- $\operatorname{SiC}_{x} \mathrm{~N}_{y}$ film with 50 at.\% of carbon, as a function of the annealing temperature. 


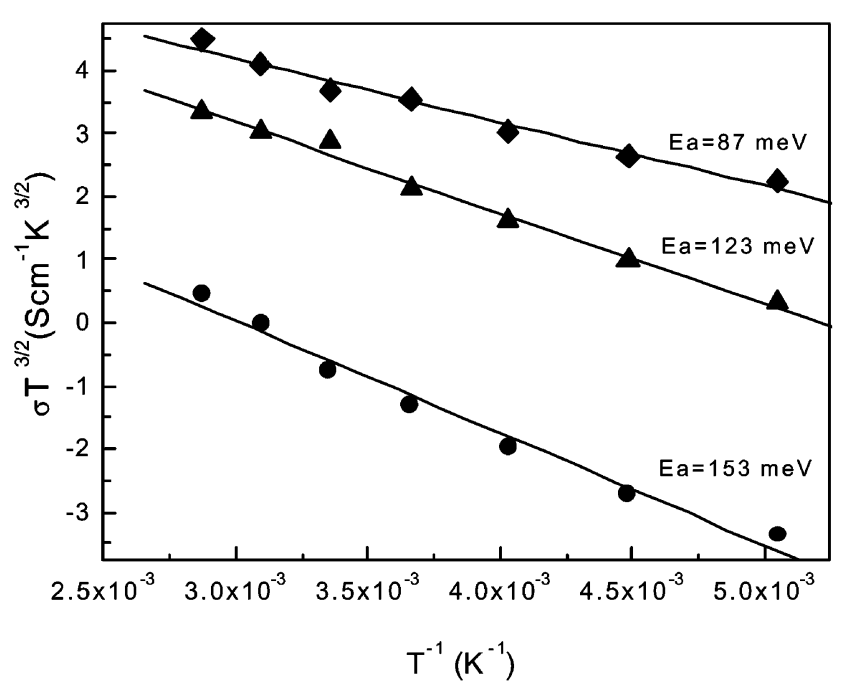

Fig. 4. Variation of the $\sigma T^{3 / 2}$ product as a function of the inverse temperature for undoped $\mathrm{a}-\mathrm{SiC}_{x} \mathrm{~N}_{y}$ films with 50 at.\% carbon, annealed at $(\bullet) 800,(\boldsymbol{\Delta}) 900$ and $(\diamond) 1000{ }^{\circ} \mathrm{C}$. The activation energies are shown on the graph for each case.

ranging from 600 to $1000{ }^{\circ} \mathrm{C}$. Fig. 4 shows the temperature dependence of $\sigma T^{3 / 2}$ for samples annealed at 800 , 900 and $1000{ }^{\circ} \mathrm{C}$. From the slope of the $\sigma T^{3 / 2}$ vs. $T^{-1}$ plots, activation energies for conduction were calculated [8]. It was found that the activation energies were decreased with higher annealing temperatures. Activation energy was $153 \mathrm{meV}$ when annealed at 800 ${ }^{\circ} \mathrm{C}$, which decreased to $87 \mathrm{meV}$ when annealed at 1000 ${ }^{\circ} \mathrm{C}$.

Undoped a-SiC $\mathrm{N}_{y}$ samples were then doped with different dopants and different dopant densities to study their effect on the electrical conductivity. A typical SIMS depth profile analysis of $\mathrm{C}, \mathrm{N}, \mathrm{O}$ and $\mathrm{P}$ ions in the a-SiC $\mathrm{N}_{y}$ samples with different incident ion fluxes (of phosphorous) and subsequent annealing at $1000{ }^{\circ} \mathrm{C}$, are shown in Fig. 5. At lower flux densities of $10^{12}$ ions $/ \mathrm{cm}^{2}$ the phosphorous signal was low, but with the flux increasing we observed a non-uniform depth profile of phosphorous. Most of the dopants were detected at a depth of $0.1 \mu \mathrm{m}$ from the sample surface and a low density of dopants at the surface was observed. Even annealing at $1000{ }^{\circ} \mathrm{C}$ could not initiate an efficient phosphorous diffusion throughout the thickness of the sample to reduce such inhomogeneity. One set of undoped film was separately implanted with $\mathrm{P}$ and $\mathrm{Mg}$ ions with a flux density of $1 \times 10^{15}$ ions $/ \mathrm{cm}^{2}$ and annealed at $900{ }^{\circ} \mathrm{C}$. The electrical conductivity increased upon $\mathrm{Mg}$ ion implantation, but $\sigma$ decreased with small amounts of $\mathrm{P}$ ion implantation. The activation energies, as found from the $\sigma T^{3 / 2}$ vs. $T^{-1}$ plots of these doped samples (Fig. 6), also show a decrease to $87 \mathrm{meV}$ with $\mathrm{Mg}$ doping in one sample whereas an increase to 182 $\mathrm{meV}$ upon $\mathrm{P}$ doping in the other, with respect to the undoped activation energy of $123 \mathrm{meV}$. Mg doping using various flux densities and subsequent annealing at $900{ }^{\circ} \mathrm{C}$, produced different electrical conductivities and activation energies (Fig. 7). Initially there was a drop in $\sigma$, but thereafter $\sigma$ increased.

\section{Discussion}

Electrical properties of amorphous materials are of particular interest since they are generally more defective
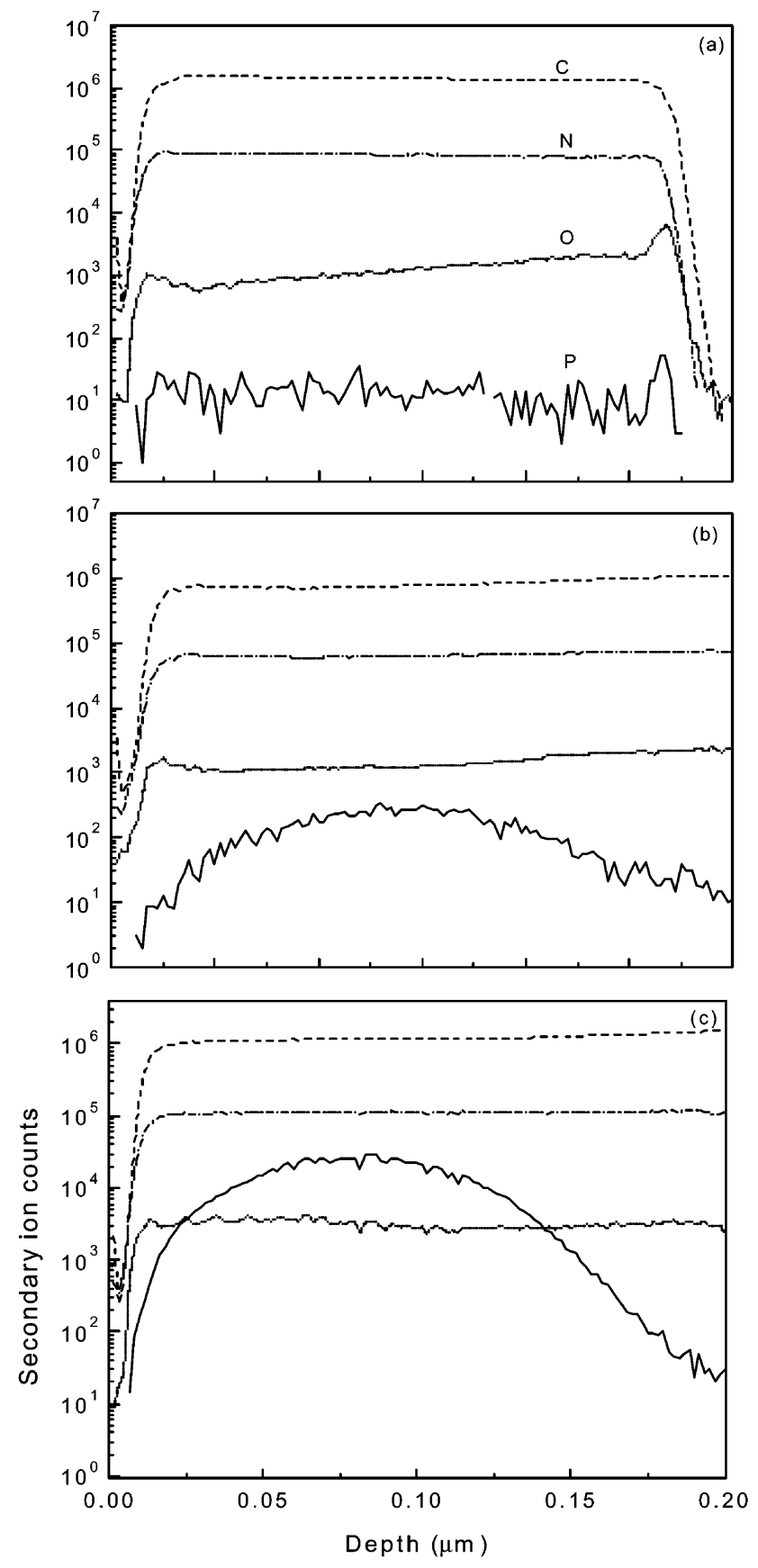

Fig. 5. A depth profile by SIMS of a-SiC $\mathrm{N}_{y}$ film annealed at 1000 ${ }^{\circ} \mathrm{C}$ and doped with $\mathrm{P}$ at (a) $1 \times 10^{12}$, (b) $1 \times 10^{14}$ and (c) $1 \times 10^{16}$ ions $/ \mathrm{cm}^{2}$. 


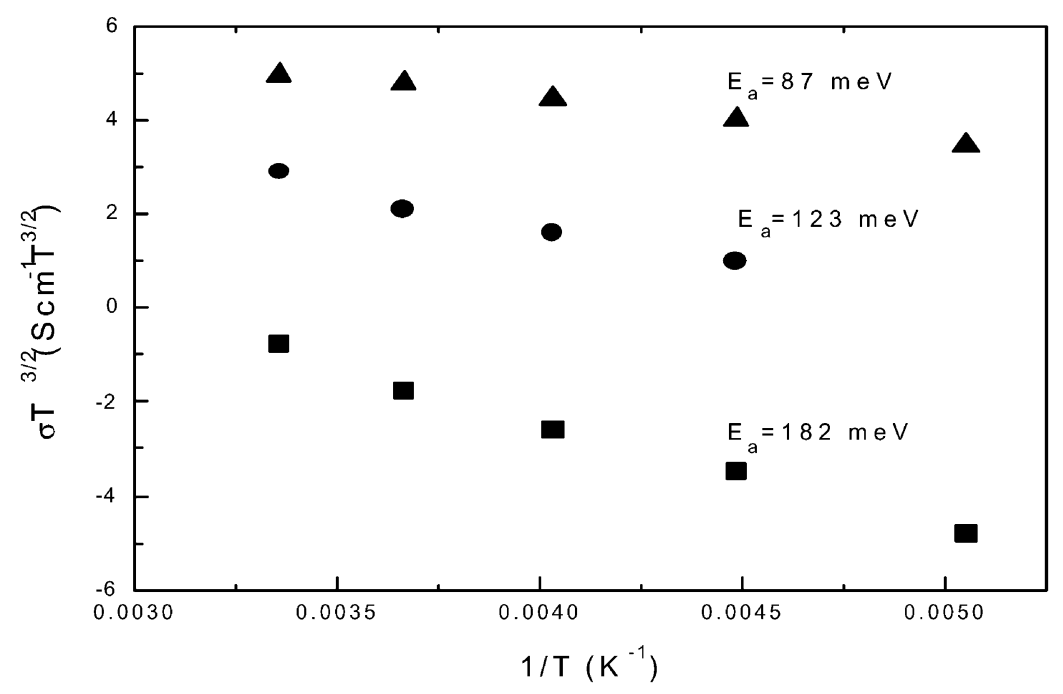

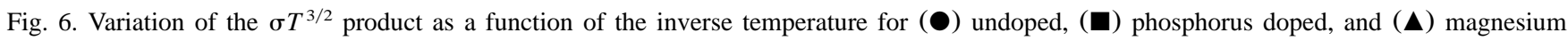
doped, a-SiC $\mathrm{N}_{y}$ films with 50 at.\% carbon, annealed at $900{ }^{\circ} \mathrm{C}$. The activation energies are shown on the graph for each case.

and have high density of mid-gap defect states, such as in amorphous silicon (a-Si). a- $\mathrm{SiC}_{x} \mathrm{~N}_{y}$ is expected to possess similar electrical conduction mechanism as that of a-Si. The deposition routes used, IBS in this case, for the preparation of a-SiC $\mathrm{N}_{y}$ films produced various defects such as dangling bonds, voids as well as lower coordinated bonds $[3,5]$. The presence of these defects in the films would reflect in their electrical conductivities. From the XPS studies we have found that in a$\mathrm{SiC}_{x} \mathrm{~N}_{y}$, carbon-carbon, carbon-nitrogen, and silicon-nitrogen bonds are most easily detected with insignificant or no presence of silicon-carbon bonds. Kinetics for the bond formation mechanism favoured the $\mathrm{C}-\mathrm{C}$ and $\mathrm{C}-\mathrm{N}$ growth, which may be responsible for the insignificant $\mathrm{Si}-\mathrm{C}$ bonds present in the system. Again from the Auger depth profile (Fig. 1) a uniform composition across the depths of the sample was found which is important to understand the electrical conductivity results of the coming sections. From Table 1 a strong increase of $\sigma$ was observed with small variations

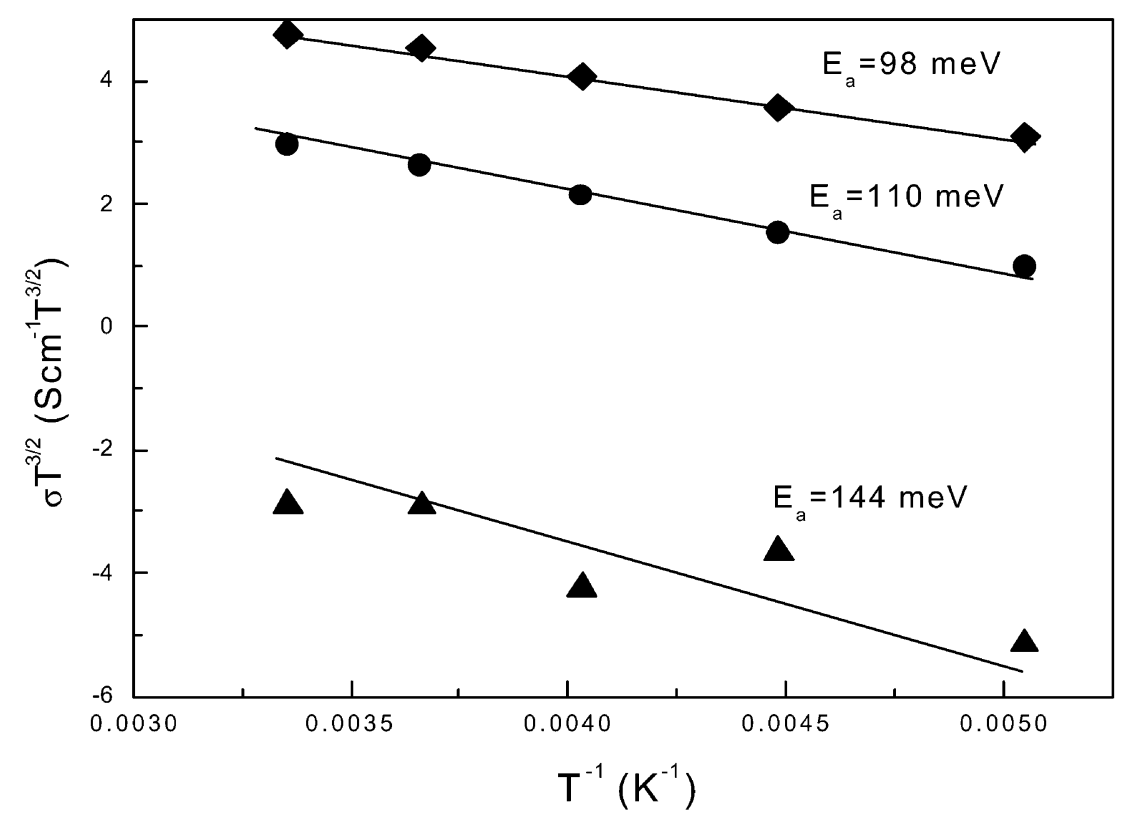

Fig. 7. Variation of the $\sigma T^{3 / 2}$ product as a function of the inverse temperature for $\mathrm{Mg}$ doped a- $-\mathrm{SiC}_{x} \mathrm{~N}_{y}$ films with 50 at. $\%$ carbon, annealed at $900{ }^{\circ} \mathrm{C}$ under incident ion flux of $(\bullet) 1 \times 10^{14},(\Delta) 1 \times 10^{15}$ and $(\downarrow) 1 \times 10^{16}$ ions $/ \mathrm{cm}^{2}$. The activation energies are shown on the graph for each case. 
in carbon content. Since the incorporated carbon links mainly with either carbon or nitrogen atoms, the increase in $\sigma$ would most probably be due to some particular bonds involving these atoms. From Fig. 2 we found that with increase in carbon content there is an increase in the $\mathrm{sp}^{2}$ bonded carbon atoms. The ratio of $\mathrm{C}\left(\mathrm{sp}^{2}\right)-\mathrm{C}: \mathrm{C}(\mathrm{sp})-\mathrm{N}$ increases from 0.8 to 1.1 , when the carbon content increase from 47 to 55 at.\%. These $\mathrm{sp}^{2}-$ carbon imparts the high electrical conductivity in graphite. Hence the increase in $\sigma$ by approximately 2 orders of magnitude is probably due to the contribution of these $\mathrm{sp}^{2}$ bonds.

The increase in the electrical conductivity of the a$\mathrm{SiC}_{x} \mathrm{~N}_{y}$ materials with annealing is expected because of the structural relaxation that results in different levels of defect removal. When annealed at different temperatures between 600 and $1000{ }^{\circ} \mathrm{C}, \sigma$ showed steady increase from $10^{-6}$ to $10^{-2} \mathrm{~S} / \mathrm{cm}$ (Fig. 3). The increase in $\sigma$ is not due to any crystallization of the material as found by X-ray diffraction and transmission electron microscopy studies. The increase in $\sigma$ is hence attributed to purely structural relaxation of the amorphous matrix.

In the range of temperatures (R.T to $-50{ }^{\circ} \mathrm{C}$ ) probed, $\sigma T^{3 / 2}$ vs. $T^{-1}$ showed a linear variation according to

$$
\sigma \propto T^{-3 / 2} \exp \left(-\frac{E_{\mathrm{a}}}{K T}\right)
$$

where $E_{\mathrm{a}}$ denotes the donor/acceptor levels with respect to the conduction/valence band. The rate of cooling will possibly affect the $\sigma$ values, but a quasi thermal equilibrium was maintained during all such measurements with sufficient relaxation times for a reliable and verifiable $\sigma$. The activation energies, calculated from the slope of the $\sigma T^{3 / 2}$ vs. $T^{-1}$ plots in Fig. 4, for undoped $\mathrm{a}-\mathrm{SiC}_{x} \mathrm{~N}_{y}$ films annealed at different temperatures also showed steady decrease with increasing annealing temperatures. This activation for electrical conduction is mainly due to hopping of carriers among the high density of states in the mobility gap. A higher slope of the $\sigma T^{3 / 2}$ vs. $T^{-1}$ plot at higher temperatures were not observed. The reduction in the activation energies indicates defect removal from the band tail states as a result of thermal annealing.

The constituent atoms in $\mathrm{a}-\mathrm{SiC}_{x} \mathrm{~N}_{y}$ films are small and covalent in nature, but a- $\mathrm{SiC}_{x} \mathrm{~N}_{y}$ films have a high electrical resistivity. Efficient doping of this kind of systems are always possible although there will be a competition between active doping and defect creation during ion implantation. While explaining the electrical conductivity data of the doped samples the effect of non-uniform dopant distribution along the thickness of the sample has to be borne in mind also. The energy loss mechanism of the impinging ions during the implantation process is responsible for such non-homogeneity, which even annealing at $1000{ }^{\circ} \mathrm{C}$ could not remove
(Fig. 5). The electrical measurements were carried out in a planar electrode configuration, where an electrically resistive channel near the surface would affect our results since the dopant density peaked at a depth of 0.1 $\mu \mathrm{m}$ from the surface of the sample (Fig. 5). Mg doping in the undoped films efficiently increases the electrical conductivity whereas $\mathrm{P}$ doping reduced the electrical conductivity to a certain extent (Fig. 6). $\mathrm{Mg}$ is a p-type dopant in our system while $\mathrm{P}$ is an n-type dopant. From Fig. 6, the indication is that the $a-\mathrm{SiC}_{x} \mathrm{~N}_{y}$ films are intrinsically p-type, so that $\mathrm{Mg}$ will further lower the activation energies hence increasing the electrical conductivity. This is only indicative since Hall measurements were not carried out on these samples. P doping on the other hand, will compensate some of these acceptor states and move the Fermi level toward midgap increasing the activation energy. This will reduce the electrical conductivity. Another reason for the decrease in $\sigma$ while doping with $\mathrm{P}$ may be the defects introduced in the network during ion implantation. It is worth mentioning here that at sufficiently high flux densities $\left(10^{16}\right.$ ions $\left./ \mathrm{cm}^{2}\right)$ of $\mathrm{P}$ ions we did find an effective increase in $\sigma$. Increasing amounts of $\mathrm{Mg}$ in the film obtained by implanting at higher flux densities will increase the electrical conductivity by more than an order of magnitude with concomitant decrease in the activation energies from 110 to $98 \mathrm{meV}$ (Fig. 7).

\section{Conclusions}

Electrical properties of undoped (as-deposited) and doped (ion-implanted) $a-\mathrm{SiC}_{x} \mathrm{~N}_{y}$ thin films have been discussed. It is found that the electrical conductivity increases with the carbon content in the films for undoped $\mathrm{SiC}_{x} \mathrm{~N}_{y}$ samples. Annealing of the films by RTP is useful in structural relaxation of the material as well as annihilation of certain defects and a resultant increase in the electrical conductivity of these films. Annealing in this case did not produce the generally observed crystallization of the amorphous matrix. Doping of the matrix by magnesium and subsequent annealing will efficiently increase the electrical conductivity of the films whereas phosphorus doping initially reduced the electrical conductivity, indicating that the films may be intrinsically p-type. Decreasing activation energy values with annealing at high temperatures reveals lowering of defect levels aiding in increased electrical conduction. The low diffusion of dopants even at high annealing temperatures speaks of the superior thermal stability of the a-SiC${ }_{x} \mathrm{~N}_{y}$ matrix.

\section{Acknowledgments}

The work was carried out under a project funded by the National Science Council, Taiwan, under Contract Nos. NSC90-2112-M002-048, and Ministry of Educa- 
tion under Contract Nos. 90-W-FA01-2-4-5. One of the authors (S.C) acknowledges the award of a post-doctoral fellowship by the National Science Council, Taiwan.

\section{References}

[1] D.Y. Lin, C.F. Li, Y.S. Huang, et al., Phys. Rev. B 56 (1997) 6498.

[2] L.C. Chen, K.H. Chen, S.L. Wei, et al., Thin Solid Films 355356 (1999) 112.

[3] S. Chattopadhyay, L.C. Chen, C.T. Wu, et al., Appl. Phys. Lett. 79 (2001) 332.
[4] L.C. Chen, C.K. Chen, S.L. Wei, et al., Appl. Phys. Lett. 72 (1998) 2463.

[5] G. Lehmann, P. Hess, J.J. Wu, et al., Phys. Rev. B 64 (2001) 165305.

[6] M. Scarlete, J. He, J.F. Harrod, I.S. Butler, NATO ASI Series E, Applied Sciences 297 (1994) 125.

[7] A. Sawaguchi, K. Toda, K. Nihara, J. Am. Ceram. Soc. 74 (1991) 1142.

[8] C. Haluschka, C. Engel, R. Riedel, J. Eur. Ceram. Soc. 20 (2000) 1365.

[9] J.J. Wu, T.R. Lu, C.T. Wu, et al., Diamond Relat. Mater. 8 (1999) 605. 